\title{
ORIGEM DOS DEPÓSITOS DE AREIAS BRANCAS NO NORDESTE DO AMAZONAS
}

\author{
ADRIANA MARIA COIMBRA HORBE ${ }^{1}$, MARCO ANTÔNIO HORBE ${ }^{2}$ \\ \& KENITIRO SUGUIO ${ }^{3}$
}

\begin{abstract}
ORIGIN OF WHITE SANDS OF THE NORTHESASTERN AMAZON STATE, BRAZIL The present analysis on the white sand deposits in northeastern Amazonas States Brazil), shows that they are subdivided in three horizons named A, B and C. The superficial horizon (A) is composed of friable sandy materials, white to gray with organic matter accumulations as wavy bands. The B horizon is essentially sandy, yellow to orange. The $\mathrm{C}$ horizon is made up of sandy argillaceous material, rich in kaolinite, $\mathrm{Al}_{2} \mathrm{O}_{3}, \mathrm{Fe}_{2} \mathrm{O}_{3}$ and $\mathrm{TiO}_{2}$. Organic matter material, forming "ortsteins" is present in the contact zone between the horizons $\mathrm{B}$ and $\mathrm{C}$. The above profile along with quartz grain corrosion in the uppermost horizon, and kaolinite-rich $\mathrm{C}$ horizon, suggest that the white sand deposits are relate to podzolic processes with differentiation of horizons and accumulation of organic matter generated by decomposition of forest litter forming Spodosols. These data relate the Spodosols to truncated profiles and, thus, their formation from the rich quartz-saprolitic horizon of the Alter do Chão Formation. This process of podzolization, that continues to the present, is very aggressive, as the studies profiles have developed in less than 3,000 years under modern forest cover.
\end{abstract}

Keywords: Podzolization process, Spodossolos, Oxisols, weathering

Resumo Os depósitos de areias brancas do nordeste do Amazonas mostram-se estruturadas em três horizontes: A, B e C. O horizonte superficial (A) é formado por areia friável, cinzenta a esbranquiçada com acumulações de matéria orgânica formando bandas onduladas de cor preta. O horizonte $\mathrm{B}$ permanece essencialmente arenoso, mas adquire coloração amarelada a alaranjada. O horizonte $\mathrm{C}$ é friável e constituído de material argilo-arenoso creme a rosado. No contato entre o horizonte B e C ocorre enriquecimento de matéria orgânica formando "ortsteins". A estruturação dos perfis, a maior corrosão dos grãos de quartzo no horizonte superficial e a predominância de quartzo, e conseqüentemente de $\mathrm{SiO}_{2}$, no horizonte $\mathrm{A}$ em detrimento da caulinita, $\mathrm{Al}_{2} \mathrm{O}_{3}, \mathrm{Fe}_{2} \mathrm{O}_{3}$ e TiO , com teores mais elevados no horizonte $\mathrm{C}$, são indícios sugestivos da sua relação com os Espodossolos. Esses dados e as características dos perfis estudados permitem relacionar os Espodossolos com os perfis truncados e, conseqüentemente, a formação destes a partir do horizonte saprolítico da Formação Alter do Chão, mais rico em quartzo e feldspatos. Esse processo de podzolização, que prossegue nos dias atuais, é muito agressivo, pois os perfis estudados foram desenvolvidos em menos de 3.000 anos, sob floresta.

Palavras-chave: Podzolização, Espodossolos, Latossolos, intemperismo

INTRODUÇÃO Em várias regiões da Amazônia ocorrem depósitos de areias brancas de gênese controversa, muitos explorados como material de construção civil. Santos (1993) sugere que algumas dessas ocorrências podem estar relacionadas à atividade eólica, enquanto Lucas et al. (1984), Chauvel et al. (1987) e Lucas (1997), entre outros, relacionam esses depósitos à intensa lixiviação de Latossolos, com geração de Espodossolos. Outra possibilidade de gênese é atribuída à erosão seletiva com retirada de material argiloso (Roose 1980).

Os Espodossolos são solos típicos de climas frios sobre os quais se desenvolvem florestas de coníferas, mas podem ocorrer em regiões tropicais úmidas sobre rochas ricas em quartzo (Schwartz 1988, Lundström et al. 2000) ou sobre saprólitos de perfis intempéricos (Thomas et al. 1999). Schwartz (1988) sugere ainda que os Espodossolos tendem a se desenvolver nas porções rebaixadas do relevo ou em pequenas depressões de platôs. São essencialmente arenosos e caracterizados pela acumulação de quartzo em detrimento dos argilominerais, especialmente da caulinita. Esse acúmulo de quartzo é atribuído à podzolização, que pressupõe a hidrólise dos argilominerais e a migração da matéria orgânica e de complexos organometálicos para subsuperfície, uma vez que a hidrólise é mais intensa que o de dissolução do quartzo (Bravard \& Righi 1989). A migração da matéria orgânica e de complexos organo-metálicos pode gerar um horizonte endurecido no contato com o lençol freático, denominado de ortstein húmico ou, ainda, bandas de coloração preta.

O nível de conhecimentos sobre a formação de Espodossolos e dos depósitos de areias brancas que ocorrem na região amazônica ainda é insuficiente para definir a sua gênese. Na área da presente investigação, Lucas et al. (1984), Chauvel et al. (1987), Lucas (1997) e Dubroeucq \& Volkoff (1998) sugerem que os Latossolos e Espodossolos fazem parte da evolução progressiva de vertentes, onde os Latossolos representariam a fase menos lixiviada pela ação de compostos orgânicos. Essa transformação é interna e relaciona-se à percolação de água, que é mais intensa quanto maior for a dissolução, à migração de soluções e os processos de neoformação que se diferenciam ao longo de vertentes.

Com base no exposto, este trabalho visa contribuir para o enten-

1 - Departamento de Geociências - Universidade Federal do Amazonas, Av. Gal. Rodrigo O. J. Ramos 3000, Japiim, 69077-000, Manaus - AM ahorbe@ufam.edu.br.

2 - CPRM - Serviço Geológico do Brasil, Av. André Araújo 2160, Aleixo, 69060-001, Manaus - AM

3 - Instituto de Geociências - Universidade de São Paulo, Rua do Lago 562, Butantã, 05508-900, São Paulo - SP 
dimento dos depósitos de areias brancas e da relação entre estas e Espodossolos e Latossolos do trecho da BR 174 entre Manaus e o km 60, onde há uma extensa exposição desse material.

LOCALIZAÇÃOEASPECTOSGERAISDAÁREA Aárea de estudo se situa na porção nordeste do Estado do Amazonas, como mostra a figura 1. Na área estudada aflora a Formação Alter do Chão, composta por arenitos arcoseanos, pelitos, argilitos, arcóseos, quartzo-arenitos e brechas intraformacionais (Cunha et al. 1994) sob a forma de estratos esbranquiçados a avermelhados, depositados em ambiente flúvio-lacustre, além de paleossolos avermelhados (Nogueira et al. 1999). As variedades de quartzoarenitos silicificados e vermelhos são denominadas informalmente de Arenito Manaus (Albuquerque 1922). Recentemente, Dino et al. (1999), por meio de estudo palinológico e estratigráfico propõem que as rochas da porção central da bacia de sedimentação da Formação Alter do Chão, onde se situa a área do presente estudo, são de idade cretácica (Aptiano/Albiano - Cenomaniano; em torno de $100 \mathrm{Ma}$ ).

A lateritização das rochas da Formação Alter do Chão propiciou o desenvolvimento de perfis imaturos (Fernandes Filho et al. 1996, Horbe et al. 2001), que se apresentam trucados e constituídos, de baixo para cima, pelos horizontes saprolítico, mosqueado e solo, com presença local de linhas de pedra. A crosta ferruginosa, quando presente, está restrita a relictos, em consequiência de intensa desferrificação da área. Apesar de incompletos, os perfis são bem desenvolvidos, com espessura superior a $3 \mathrm{~m}$, os menos espessos situados em áreas onde houve truncamento mais profundo.

As unidades pedológicas da área consistem de Latossolos amarelados, argilosos a argilo-arenosos, Argissolos arenosos a arenoargilosos amarelados e as areias brancas (Espodossolos?)

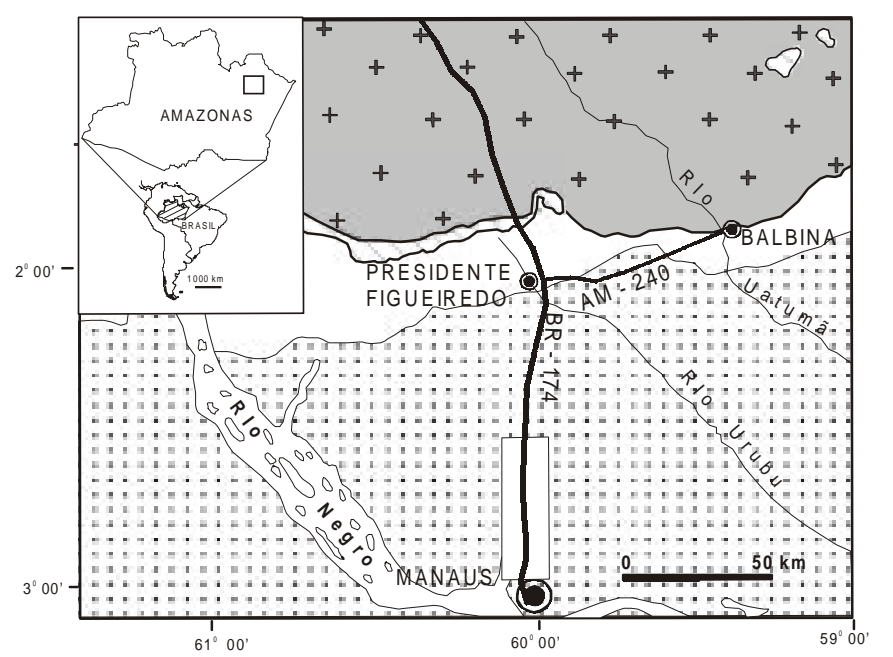

Formação Alter do Chão (Cretáceo Superior)

Formação Nhamundá (Siluriano Inferior)

Formação Prosperança (Neoproterozóico)

Supergrupo Uatumã (Mesoproterozóico)

Rodovia $\square$ Área de estudo $ح$ Drenagem

Figura 1 - Mapa litoestratigráfico e de localização da área de estudo.
(RADAMBRASIL 1978). Para Leal (1996), na região de Manaus, os Latossolos predominam sobre Espodossolos.

As unidades morfoesculturais que caracterizam o relevo da região são colinas de extensão reduzida, com comprimentos de até $150 \mathrm{~m}$, com topos aplanados e densidade média de drenagem, com vales em forma de V. A norte e leste da área estudada ocorrem extensos platôs com largura em torno de 1 a $2 \mathrm{~km}$ e comprimento de 3 a 12 km (Horbe et al. 2001, Sarges 2001). Os platôs são sustentados por crostas lateríticas ferruginosas e ferro-aluminosas, cobertas por Latossolos amarelados (Horbe et al. 2001). O grau de entalhamento da drenagem diminui consideravelmente de norte para sul, com desníveis máximos de até $180 \mathrm{~m}$ na parte norte da área e valores mínimos em torno de $60 \mathrm{~m}$ nas proximidades de Manaus.

O clima na região é tropical quente e úmido, com temperatura média anual de $26^{\circ} \mathrm{C}$ e precipitação média em torno de $1.800 \mathrm{~mm} /$ ano. A estação chuvosa estende-se de dezembro a maio e o período mais seco ocorre normalmente entre agosto e outubro. Este clima agressivo favorece o desenvolvimento de intenso intemperismo químico e é o responsável pela implantação e conservação da exuberante cobertura vegetal.

MATERIAIS E MÉTODOS No trecho da BR-174 situado entre os kms 0 e 60 afloram doze ocorrências de areias brancas, das quais selecionou-se 5 locais com os perfis mais completos, localizados nos Kms 6,5, 10,5, 30, 35,5 e 56,5. Destes, apenas no perfil 1, foram quantificadas a composição mineral e química. A composição mineral foi obtida por difração de raios-X e as propriedades texturais por microscopia eletrônica.

Dados de composição química sobre óxidos de elementos maiores e elementos traço ( $\mathrm{Ni}, \mathrm{Co}, \mathrm{Cr}, \mathrm{V}, \mathrm{Ce}, \mathrm{Nd}, \mathrm{Ba}, \mathrm{La}, \mathrm{Nb}, \mathrm{Zr}, \mathrm{Y}, \mathrm{Pb}$, $\mathrm{Zn}, \mathrm{S}, \mathrm{Cl}$ e Th) foram obtidas por fluorescência de raios-X que, juntamente com os da difração, permitiram obter a composição mineral quantitativa das amostras analisadas. Os grupos orgânicos foram identificados por infravermelho e quantificados por titulação.

Os fatores de enriquecimento foram obtidos em relação ao horizonte $\mathrm{C}$ e considerando o $\mathrm{Zr}$ como imóvel. Esses fatores foram calculados mediante o cálculo da razão da concentração dos elementos nos horizontes A e B em relação a $\mathrm{C}(\mathrm{A} / \mathrm{C} \mathrm{e} \mathrm{B/C})$ e multiplicado pela razão do $\mathrm{Zr}$ em $\mathrm{C}$ em relação a esse elemento nos demais horizontes ( $\mathrm{Zr}$ em C/Zr em A e Zr em C/Zr em B).

As determinações de idade foram realizadas no Laboratório de Radiocarbono do Centro de Energia Nuclear na Agricultura (CENAUSP). As idades são expressas em anos antes do presente (AP) e normalizadas segundo $\mathrm{d}^{13} \mathrm{C}_{\mathrm{PDB}}$. Foram analisadas uma amostra de carvão e três de areias ricas em matéria orgânica e ortstein.

RESULTADOS OBTIDOS E DISCUSSÕES Caracterização dos perfis estudados As ocorrências de areias brancas estendem-se, na região estudada, por vasta área sobre a Formação Alter do Chão, abrangendo os municípios de Manaus, Itacoatiara, Manacapuru e Iranduba. Nos locais de ocorrência mais significativa, a sua identificação é facilitada pelo desenvolvimento de vegetação de campina ou cerrado com floresta aberta na periferia.

Os cinco perfis estudados contém os horizontes A, B e C (Fig. 2). O horizonte $A$, superficial, tem espessura de até $5 \mathrm{~m}$ e consiste de material arenoso friável, cinzento (Fig. 2; perfis 1 e 2) a esbranquiçado (Figs. 2, 3A e 3B; perfis 3, 4 e 5). As acumulações de matéria orgânica são pretas e geralmente ocorrem em bandas onduladas, com até $4 \mathrm{~mm}$ de espessura (Figs. 3C e 3D). Algumas 


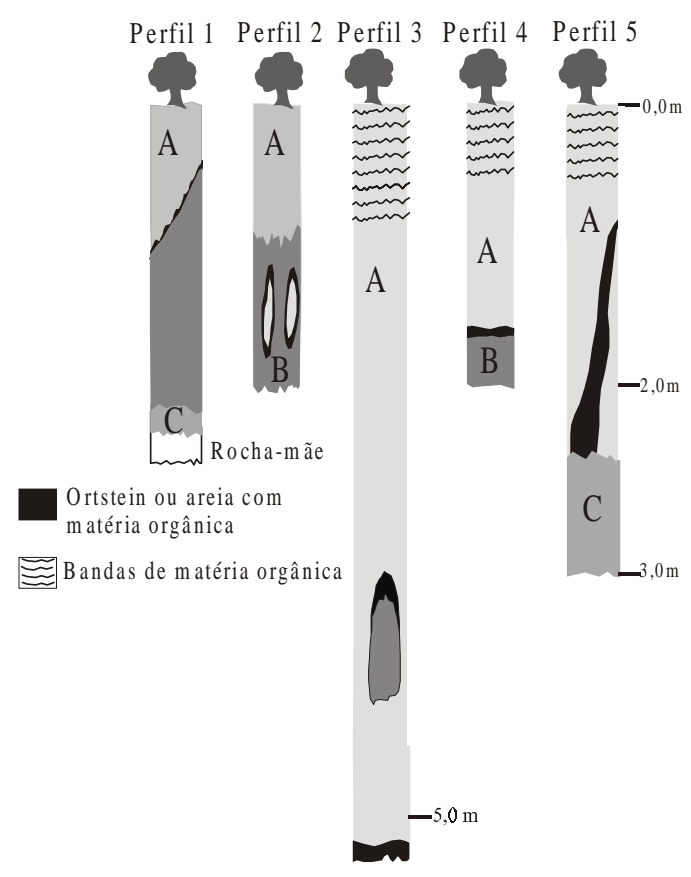

Figura 2 - Estruturação esquemática dos perfis estudados. A, Be $C$ representam os horizontes.

bandas são endurecidas pela presença de óxi-hidróxidos de ferro, os quais conferem coloração amarelada a castanha ao material arenoso adjacente.

Em profundidade, o perfil mantêm-se arenoso, mas passa a amarelado a alaranjado, característicos do horizonte B (Figs. 2, 3B, 3C, 3E, 3F). O contato entre os horizontes A e B é abrupto (Fig. 3B e $3 \mathrm{C})$ e contem clastos do último no horizonte superior cinzento a esbranquiçado (Fig. 3C, 3E, 3F). Alguns clastos apresentam, na sua parte superior, auréolas pretas resultantes da acumulação de matéria orgânica (Figs. 3E e 3F).

Envolvidas pelo material arenoso amarelado do horizonte B, ocorrem feições subverticais, com até $30 \mathrm{~cm}$ de comprimento, compostas por material arenoso cinzento a esbranquiçado e envoltas, total a parcialmente, por faixa externa também arenosa, porém mais escura devido à presença de matéria orgânica (Figs. 4A e 4B). Essas feições estão, provavelmente, relacionadas a vazios resultantes da decomposição de raízes, com acumulação de matéria orgânica nas paredes preenchimento posterior por material arenoso do horizonte A. Chauvel et al. (1987) atribui essas feições à migração da matéria orgânica.

O horizonte C ocorre nos perfis 1 e 5 (Fig. 2). É friável e constituído de material argilo-arenoso creme a rosado. Na zona de contato entre os horizontes B e C geralmente há acumulação de matéria orgânica em níveis pretos com até $10 \mathrm{~cm}$ de espessura, os quais estão, em alguns locais, endurecido na forma de verdadeiros ortsteins (Fig. 5A). Estes níveis têm arcabouço formado por grãos de quartzo com bordas corroídas, de granulação heterogênea, cimentados por matéria orgânica, a qual também preenche fraturas (fig. 5b), e cuja concentração resulta de iluviação.

Em alguns locais, o caráter friável dos horizontes A e B facilita a remoção natural dos níveis superiores e exposição do horizonte $\mathrm{C}$. Onde aflora, localmente ocorrem estruturas circulares, com até 35 $\mathrm{cm}$ de diâmetro, cujo núcleo está preenchido por material arenoso preto, rico em matéria orgânica, e que representam, provavelmente, restos de troncos de árvores (Fig. 6A).

A rocha fresca, encontrada somente no perfil 1, é de arenito silicificado branco com manchas rosadas, correlacionável ao Arenito Manaus e é composto por grão de quartzo com cimento sílico-ferruginoso (Franzinelli \& Rossi 1996).

Ao longo dos vales e nas voçorocas freqüentemente ocorrem lentes de material arenoso cinza escuro a preto, rico em matéria orgânica e com estratificação plano-paralela (Fig. 6B). Este material provavelmente resulta da remobilização ou iluviação atual da matéria orgânica para as porções mais baixa, pela ação da água da chuva.

Composições mineralógicas e granulométricas O quartzo leitoso é o mineral mais abundante em todos os perfis. No perfil 1, considerado o mais representativo da área, foi feita a quantificação mineralógica (Tab. 1). As proporções de quartzo aumentam do horizonte C (74\%) para o A $(98 \%)$. A caulinita do horizonte C atinge até $25 \%$. Além desses minerais, ocorrem ainda grãos de feldspato potássico, opacos, diatomáceas, fitólitos de sílica e oólitos de matéria orgânica, em proporções inferiores a 1\% (Fig. 7).

A figura 8 apresenta as freqüências granulométricas dos perfis estudados. Nos perfis 1, 3, 4 e 5 foram feitos ensaios em todos os horizontes, enquanto no perfil 2 determinou-se somente a distribuição granulométrica da feição que ocorre no horizonte B (Fig. 4). A classe granulométrica mais abundante em todos os horizontes é a areia, com destaque para a de granulometria média $(0,50$ a 0,25 $\mathrm{mm}$ ) que corresponde entre $20 \%$ e $50 \%$ do material total (Fig. 8), seguida da grossa $(1,00$ a $0,50 \mathrm{~mm})$ e fina $(0,25$ a $0,125 \mathrm{~mm})$. A fração pelítica representa menos de $2 \%$ e grânulos e seixos maiores que $2 \mathrm{~mm}$, sempre de quartzo, compõem até $23 \%$ do material no horizonte A do perfil 3.

As variações entre as amostras são acentuadas, mas, em geral, nos perfis com horizonte $C$ a proporção de areia média $(0,50$ a 0,25 $\mathrm{mm}$ ) decresce deste para o B (perfis 1 e 4), exceto no perfil 5 que apresenta a menor proporção dessa fração (31\%), mas contem $36 \%$ de areia grossa $(1,00$ a $0,50 \mathrm{~mm})$. Do horizonte B para o A, a quantidade de areia média também diminui nos perfis 3,4 e 5 e mantém-se constante no perfil 1. As demais frações apresentam distribuições aleatórias ao longo dos perfis. Entre estas classes granulométricas, há uma tendência da fração 0,50-0,25 mm diminuir para o topo do perfil, o que pode indicar corrosão dos grãos de quartzo, como sugerem as formas angulosas a subangulosas e a baixa esfericidade dos grãos (Figs. 7A e 7B). Nas demais frações há um comportamento aleatório, tanto entre os horizontes de um mesmo perfil como entre eles.

Características químicas $\mathrm{O}$ perfil 1 , o mais completo, foi selecionado como representativo da composição química dos materiais estudados. Os dados constam das Tabelas 2 e 3. Em todos os horizontes, $\mathrm{SiO}_{2}$ é o componente principal, refletindo o caráter essencialmente quartzoso dos horizontes. Os teores de $\mathrm{Al}_{2} \mathrm{O}_{3}$ são variáveis, desde menos de $1 \%$ no horizonte $\mathrm{A}$, até cerca de $10 \%$ no C, em função do aumento de caulinita em direção aos horizontes inferiores. $\mathrm{Fe}_{2} \mathrm{O}_{3}$ e TiO ${ }_{2}$ ocorrem em proporções inferiores a $1 \%$. O pequeno aumento de $\mathrm{Fe}_{2} \mathrm{O}_{3}$ no horizonte $\mathrm{A}$, mais rico em matéria orgânica, sugere uma correlação entre ambos, enquanto o $\mathrm{TiO}_{2}$, decrescente para o topo do perfil, indica a destruição dos minerais opacos possíveis portadores desse elemento. Os demais constituintes $\left(\mathrm{CaO}, \mathrm{MgO}, \mathrm{Na}_{2} \mathrm{O}, \mathrm{K}_{2} \mathrm{O}\right.$ e $\left.\mathrm{P}_{2} \mathrm{O}_{5}\right)$ apresentam em teores muito baixos $(<0.01 \%)$. 

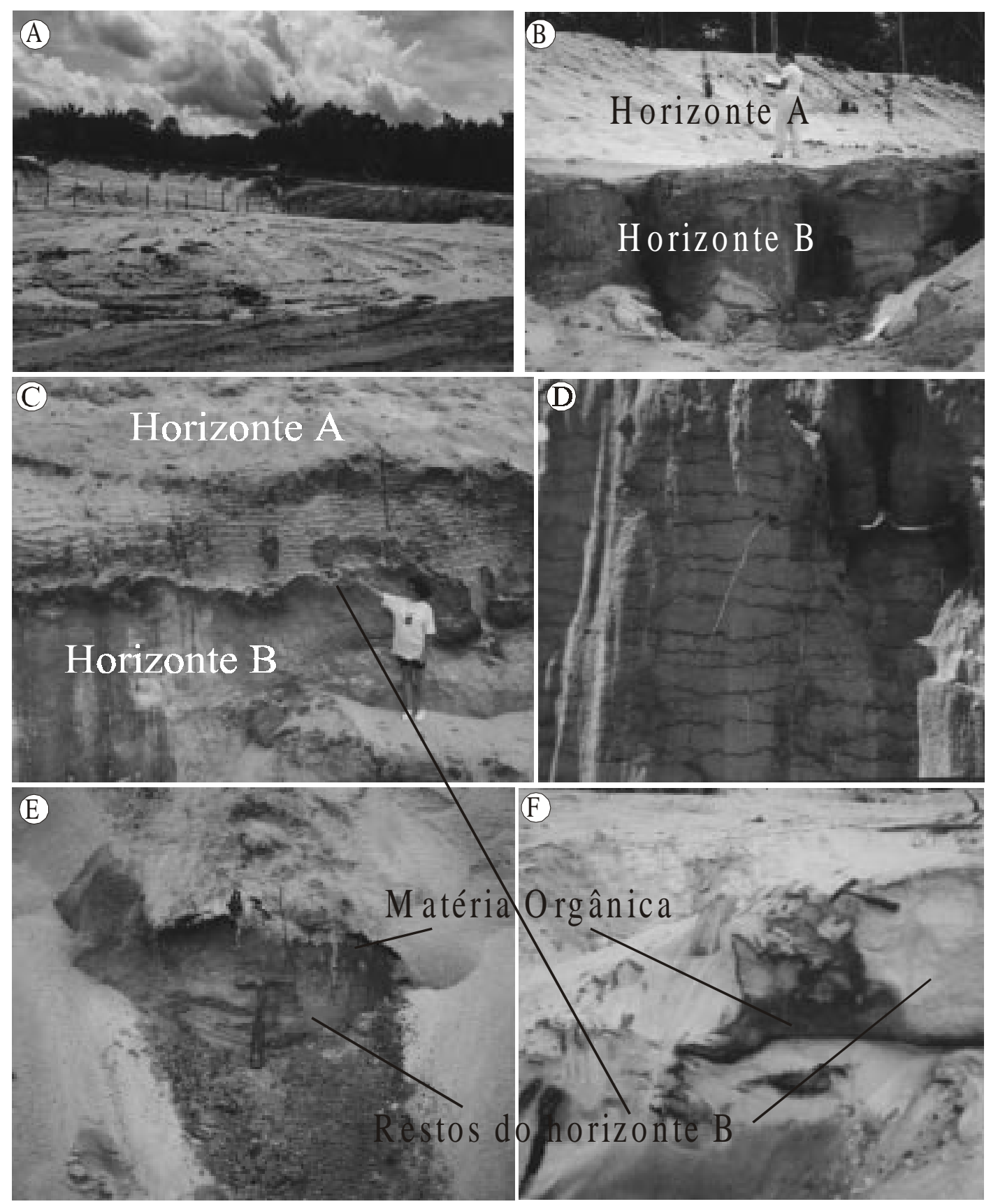

Figura 3 - A - Vista geral do areial do $\mathrm{km}$ 30, o barranco ao fundo representa o perfil 3; B - Estruturação de um Espodossolo localizado no $\mathrm{km} 13$ onde é possível diferenciar na porção superior os horizonte A, de coloração cinza clara, e o B sotoposto e mais escuro devido a sua cor ocre-amarela; $C$ - Contato entre os horizontes $A$ e $B$. São visiveis os clastos de material do horizonte $B$ contido no A; $D$ - Bandas onduladas de matéria orgânica no horizonte A do perfil 3; E e F - Horizonte A contendo clastos de material ocre-amarelado a cinzento, provenientes do horizonte B. Observa-se franja escura de matéria orgânica envolvendo parcialmente esses clastos.

As correlações negativas $\mathrm{SiO}_{2} \times \mathrm{Al}_{2} \mathrm{O}_{3}$ e $\mathrm{TiO}_{2} \times \mathrm{SiO}_{2}$, e positiva $\mathrm{TiO}_{2} \times \mathrm{Al}_{2} \mathrm{O}_{3}$, sugerem progressivas transformações químicas que ao longo do perfil, pois do horizonte $\mathrm{C}$ ao $\mathrm{A}$ ocorre aumento gradual de $\mathrm{SiO}_{2}$ e diminuição mais acentuada de $\mathrm{Al}_{2} \mathrm{O}_{3}$ e $\mathrm{TiO}_{2}$ em relação ao $\mathrm{Fe}_{2} \mathrm{O}_{3}$ (Fig. 9).

As bandas pretas onduladas contém $0,05 \%$ a $0,20 \%$ de carbono orgânico, entre 50 ppm e 1.160 ppm de Fe total e menos de 5 ppm de Mn. Segundo De Coninck (1980), o Fe auxilia na imobilização da matéria orgânica (quelação), o que poderia explicar a presença dessas bandas no horizonte A.

O acúmulo de Fe e, eventualmente Mn, na matéria orgânica em bandas pode estar relacionado ou a variações granulométricas, com a alternância de material fino e grosso, à ação de termitas ou, ainda, à migração de colóides entre os grãos, com colmatação dos 


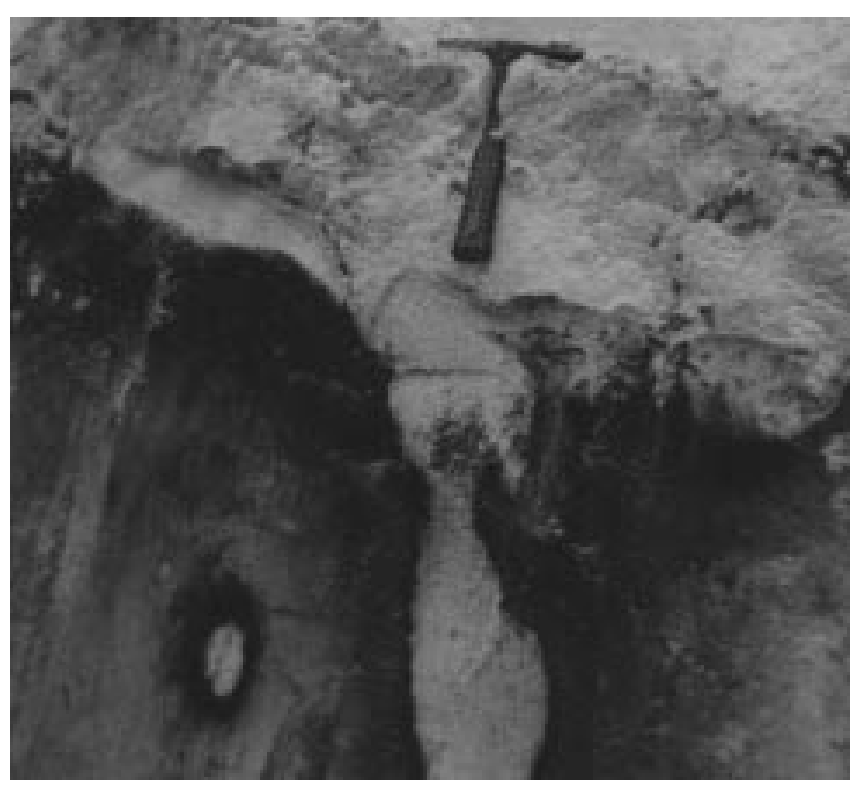

Figura 4 - Feição vertical desenvolvida no horizonte B do perfil 2. A porção mais escura consiste de material arenoso mais rico em matéria orgânica disposta em franja externa, enquanto a porção interna é arenosa cinza-esbranquiçada e correlacionada ao horizonte A.
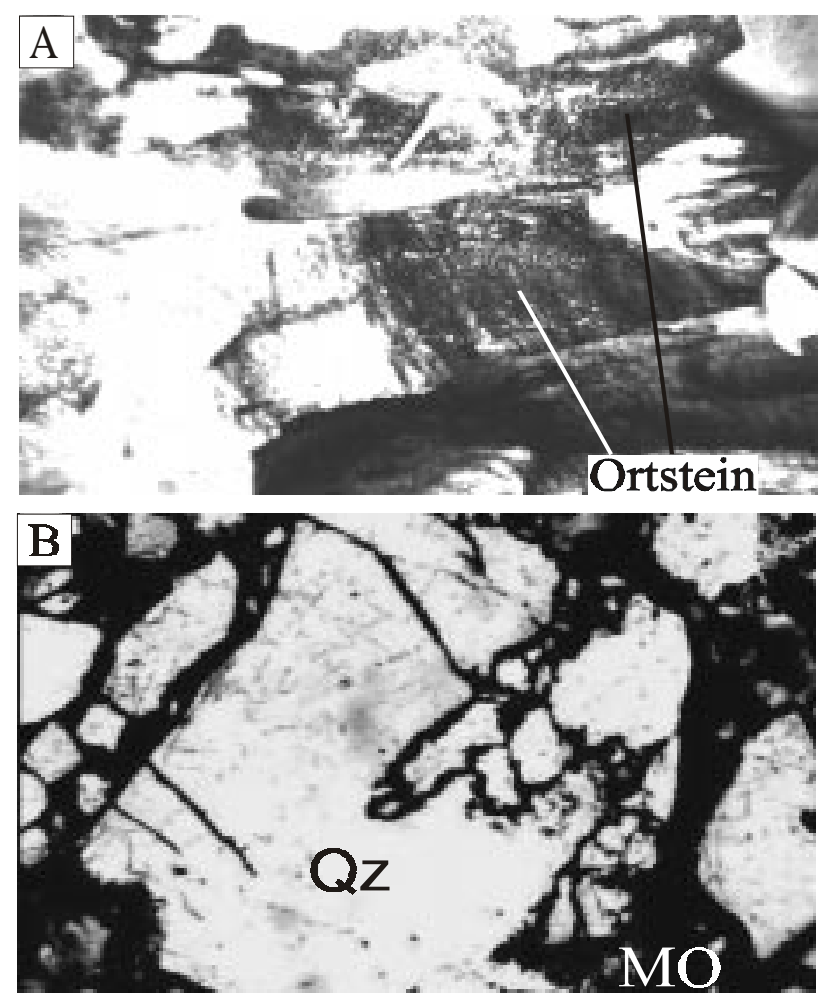

Figura 5 - Aspecto dos níveis de ortstein encontrados no perfil 3; $B$ - Fotomicrografia onde observam-se os grãos de quartzo corroídos, com fraturas preenchidas por matéria orgânica e o cimento constituído desse mesmo material. Aumento de 40 vezes.
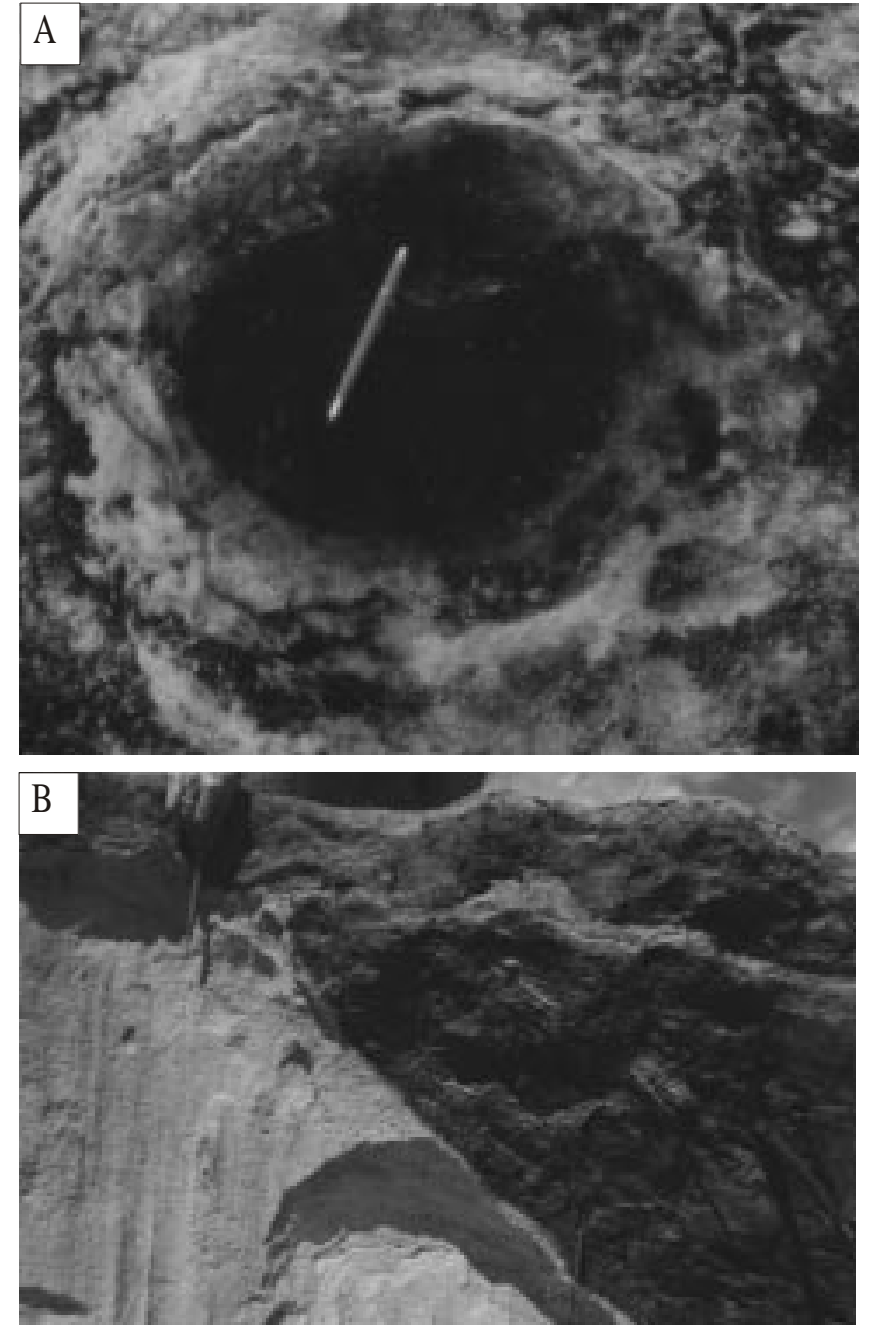

Figura 6 - A- Estrutura circular no horizonte $C$ com núcleo preenchido por material arenoso preto rico em matéria orgânica representando, provavelmente, moldes de troncos de árvores; $B$ Lente de material arenoso rico em matéria orgânica com estratificação plano-paralela que ocorre nas porções rebaixadas e voçorocas e que representam remobilização atual dos Espodossolos.

espaços intergranulares por iluviação (Campy \& Macaire 1986). Este último mecanismo parece ser o mais provável, pois nas investigações realizadas não foram observadas variações granulométricas significativas, nem feições associadas com termitas.

Dentre os 21 elementos-traço analisados, somente $\mathrm{Cr}, \mathrm{Zr}, \mathrm{Ba}, \mathrm{S}$, $\mathrm{Cl}$ e, secundariamente, $\mathrm{Ce}$ e La, exibem teores acima do limite de detecção (Tab. 3) e permitem interpretar as suas distribuições ao longo do perfil. O Zr ocorre em concentrações relativamente mais elevadas, e estaria ligado à presença de zircão. Os de $\mathrm{Cr}$ podem estar relacionados a cromita. Os teores de $\mathrm{Cr}, \mathrm{Ba}, \mathrm{S}$ e $\mathrm{Cl}$ são mais elevados no nível mais rico em matéria orgânica, o que sugere afinidade entre si (Tab. 3). O Ce e La, com teores pouco mais elevados nos horizontes mais ricos em caulinita, denotam correlação positiva desses elementos com o argilomineral. 

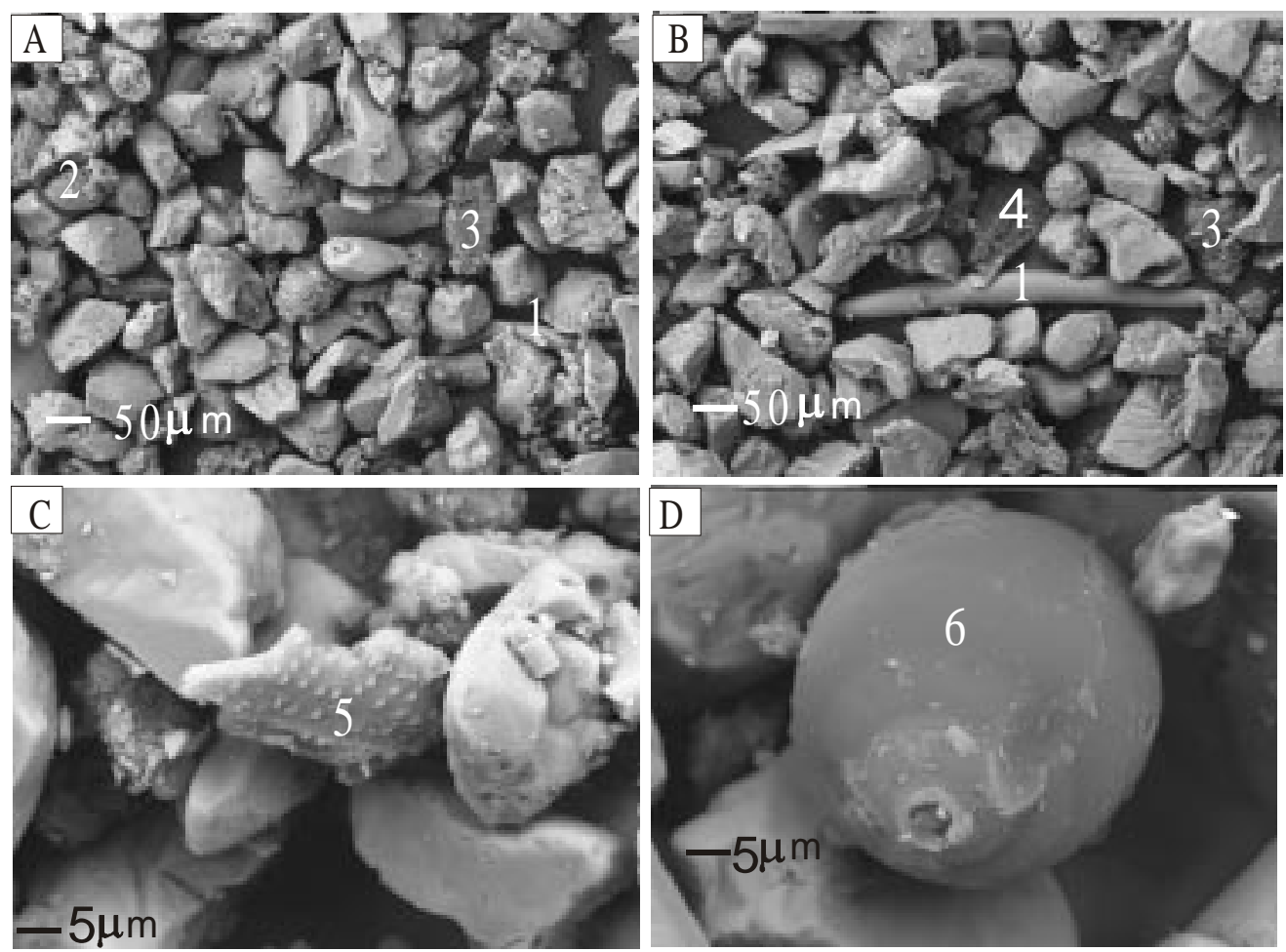

Figura 7 - Grãos de quartzo com formas angulosas a subangulosas, fitólitos de sílica (1); oólitos de matéria orgânica (2 e 6); agregados de caulinita (3); feldspato potássico (4) e diatomáceas (5) encontrados no horizonte A.

Tabela 1 - Composição mineralógica do perfil 1, em \%.

\begin{tabular}{|ccc|}
\hline Horizontes & Quartzo & Caulinita \\
\hline A & 98 & 1 \\
Nível com areia orgânica & 97 & 2 \\
A & 91 & 8 \\
B & 84 & 15 \\
C & 74 & 25 \\
\hline
\end{tabular}

Hematita+goethita, k-feldspato, clorita com menos de $1 \%$

Tabela 2 - Composição química do perfil 1, em \% em peso.

\begin{tabular}{|cccccccc|}
\hline Horizontes & $\mathrm{SiO}_{2}$ & $\mathrm{Al}_{2} \mathrm{O}_{3}$ & $\mathrm{Fe}_{2} \mathrm{O}_{3}$ & $\mathrm{MnO}$ & $\mathrm{TiO}_{2}$ & $\mathrm{MgO}$ & $\mathrm{PF}$ \\
\hline $\mathrm{A}$ & 98,02 & 0,30 & 0,41 & 0,08 & 0,05 & 0,09 & 1,01 \\
Nível com areia orgânica & 95,67 & 0,90 & 0,59 & 0,08 & 0,08 & 0,11 & 2,54 \\
$\mathrm{~A}$ & 95,29 & 2,95 & 0,45 & 0,08 & 0,13 & 0,11 & 0,95 \\
$\mathrm{~B}$ & 90,78 & 5,84 & 0,42 & 0,08 & 0,20 & 0,14 & 2,50 \\
$\mathrm{C}$ & 86,89 & 9,91 & 0,34 & 0,08 & 0,26 & 0,16 & 2,34 \\
\hline
\end{tabular}

$\mathrm{CaO}, \mathrm{MgO}, \mathrm{Na}_{2} \mathrm{O}, \mathrm{K}_{2} \mathrm{O}$ e $\mathrm{P}_{2} \mathrm{O}_{5}$ abaixo de $0,01 \%$

Tabela 3 - Concentração dos elementos-traço em ppm do perfil 1.

\begin{tabular}{|ccccccccccccccccc|}
\hline Horizontes & $\mathrm{Ni}$ & $\mathrm{Co}$ & $\mathrm{Cr}$ & $\mathrm{V}$ & $\mathrm{Ce}$ & $\mathrm{Nd}$ & $\mathrm{Ba}$ & $\mathrm{La}$ & $\mathrm{Nb}$ & $\mathrm{Zr}$ & $\mathrm{Y}$ & $\mathrm{Pb}$ & $\mathrm{Zn}$ & $\mathrm{S}$ & $\mathrm{Cl}$ & $\mathrm{Th}$ \\
\hline $\mathrm{A}$ & 7 & 1 & 340 & 2 & 2 & $*$ & 26 & 2 & 3 & 326 & $*$ & 2 & 1 & 22 & 20 & $<2$ \\
Nível com areia orgânica & 9 & 2 & 484 & 4 & 2 & $*$ & 29 & 3 & 1 & 268 & $*$ & 2 & 5 & 58 & 27 & $<2$ \\
$\mathrm{~A}$ & 5 & 1 & 228 & 5 & 10 & 5 & 30 & 10 & 7 & 335 & 2 & 3 & $*$ & 24 & 26 & 3 \\
$\mathrm{~B}$ & 6 & 2 & 312 & 4 & 6 & 2 & 31 & 5 & 6 & 253 & 1 & 3 & 1 & 8 & 22 & $<2$ \\
$\mathrm{C}$ & 5 & 3 & 163 & 6 & 20 & 6 & 32 & 20 & 8 & 315 & 3 & 3 & 5 & 18 & 16 & 3 \\
\hline
\end{tabular}

* e $\mathrm{Sr}, \mathrm{Rb}, \mathrm{As}, \mathrm{Cu}, \mathrm{Sc}$ inferiores a $1 \mathrm{ppm}$ 

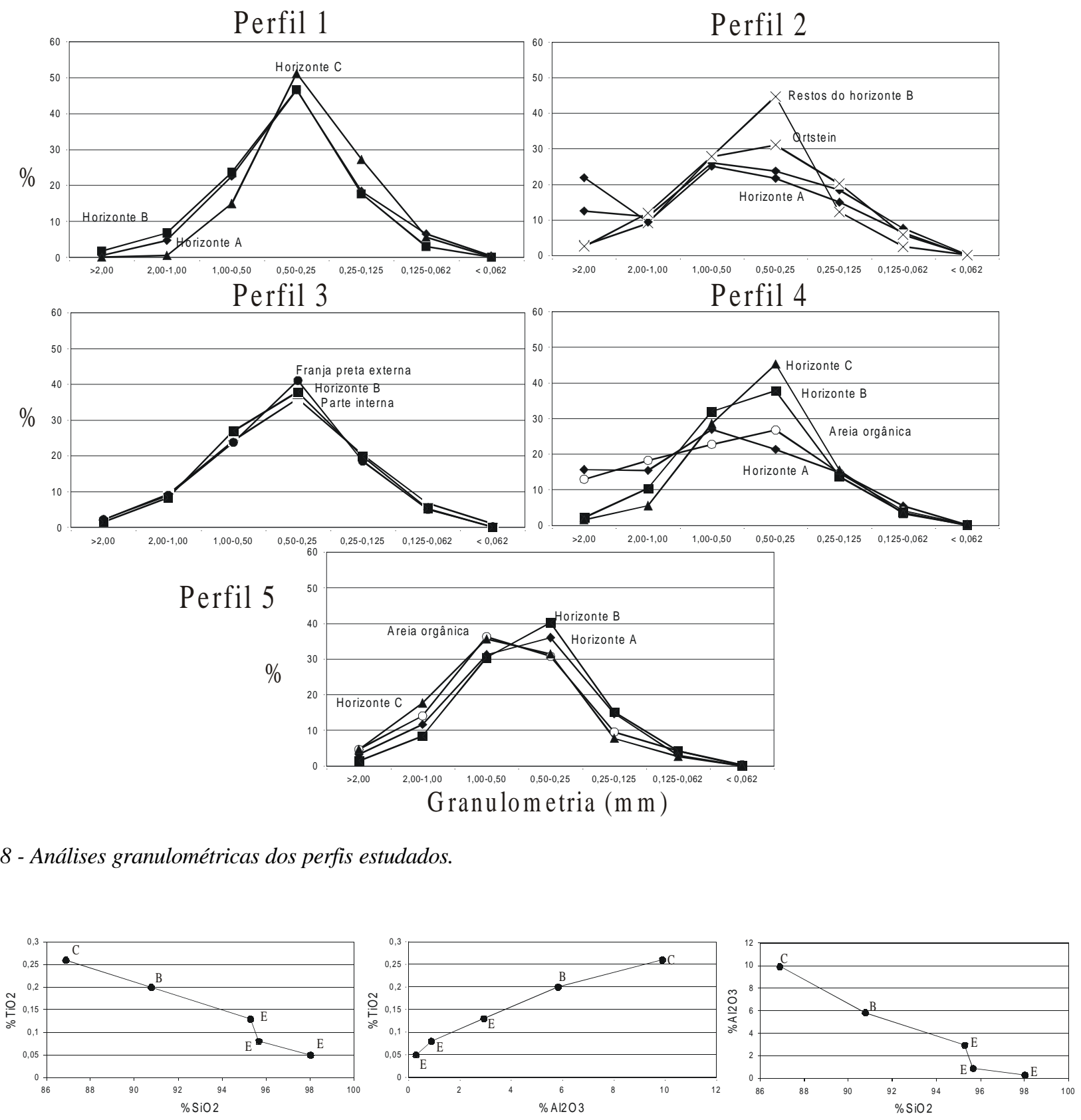

Figura 9 - Correlação $\mathrm{SiO}_{2} x \mathrm{Al}_{2} \mathrm{O}_{3}, \mathrm{TiO}_{2} x \mathrm{SiO}_{2}$ e $\mathrm{TiO}_{2} x \mathrm{Al}_{2} \mathrm{O}_{3}$ do perfil 1. A, B e C representam cada um dos horizontes.

Os fatores de enriquecimento em relação ao $\mathrm{Zr}$ (Tabela 4) indicam que somente $\mathrm{SiO}_{2}, \mathrm{Fe}_{2} \mathrm{O}_{3}, \mathrm{Ni}, \mathrm{Cr}$ e, em parte, $\mathrm{MnO}$ enriquecem do horizonte $\mathrm{C}$ para $\mathrm{A}$, o que demonstra a intensa lixiviação durante a formação deste perfil (Tab. 4). No nível mais rico em matéria orgânica do horizonte $\mathrm{A}$, além dos elementos citados, há também enriquecimento em $\mathrm{Ba}, \mathrm{Zn}, \mathrm{S} \mathrm{e} \mathrm{Cl}$, o qual sugere associação entre os mesmos, provavelmente na forma de complexos organo-metálicos.

As correlações químicas e a pequena variação nos teores dos elementos-traço nos diferentes horizontes sugerem evolução dos perfis estudados in situ, com desenvolvimento progressivo dos horizontes superiores a partir dos inferiores e, ao longo dos quais, as areias quartzosas puras representam o produto final de lixiviação intempérica.

A matéria orgânica pode acumular-se parcialmente, formando as bandas que ocorrem no horizonte $\mathrm{B}$, ou ser totalmente lixiviada, concentrando-se após iluviação no contato entre a zona quartzosa mais porosa (horizonte $\mathrm{A}$ ) e a mais argilosa (horizonte $\mathrm{C}$ ), formando os ortsteins. A lixiviação da matéria orgânica em profundidade e a formação das bandas de areias orgânicas e do "ortstein", sugerem condições não hidromórficas no desenvolvimento dos perfis $3,4 \mathrm{e}$ 5 , refletindo condições de clima relativamente seco que possibilitou a cimentação dos grãos de quartzo com matéria orgânica, conforme observado por Schwartz (1988) em perfis similares. Nos perfis 1 e 2, a cor cinzenta exibida pelo horizonte A resulta de menor lixiviação da matéria orgânica, indicativo da presença de ambiente mais 
Tabela 4 - Fatores de enriquecimento do perfil 1, em relação ao zircônio.

\begin{tabular}{|cccccccc|}
\hline Horizontes & $\mathrm{SiO}_{2}$ & $\mathrm{Al}_{2} \mathrm{O}_{3}$ & $\mathrm{Fe}_{2} \mathrm{O}_{3}$ & $\mathrm{MnO}$ & $\mathrm{TiO}_{2}$ & $\mathrm{MgO}$ & $\mathrm{PF}$ \\
\hline $\mathrm{A}$ & 1,09 & 0,03 & 1,17 & 0,97 & 0,19 & 0,55 & 0,42 \\
Nível com areia orgânica & 1,30 & 0,11 & 2,05 & 1,18 & 0,36 & 0,81 & 1,28 \\
$\mathrm{~A}$ & 1,03 & 0,28 & 1,24 & 0,94 & 0,47 & 0,65 & 0,38 \\
$\mathrm{~B}$ & 1,31 & 0,74 & 1,54 & 1,25 & 0,96 & 1,09 & 1,34 \\
$\mathrm{C}$ & 1,00 & 1,00 & 1,00 & 1,00 & 1,00 & 1,00 & 1,00 \\
\hline
\end{tabular}

\begin{tabular}{|cccccccccccccccc|}
\hline Horizontes & $\mathrm{Ni}$ & $\mathrm{Co}$ & $\mathrm{Cr}$ & $\mathrm{V}$ & $\mathrm{Ce}$ & $\mathrm{Nd}$ & $\mathrm{Ba}$ & $\mathrm{La}$ & $\mathrm{Nb}$ & $\mathrm{Y}$ & $\mathrm{Pb}$ & $\mathrm{Zn}$ & $\mathrm{S}$ & $\mathrm{Cl}$ & $\mathrm{Th}$ \\
\hline $\mathrm{A}$ & 1,36 & 0,32 & 2,02 & 0,32 & 0,10 & $*$ & 0,79 & 0,10 & 0,36 & $*$ & 0,65 & 0,19 & 1,19 & 1,21 & $*$ \\
Nível com areia orgânica & 2,12 & 0,79 & 3,50 & 0,79 & 0,12 & $*$ & 1,07 & 0,18 & 0,15 & $*$ & 0,79 & 1,18 & 3,80 & 1,99 & $*$ \\
$\mathrm{~A}$ & 0,94 & 0,31 & 1,31 & 0,78 & 0,47 & 0,78 & 0,88 & 0,47 & 0,82 & 0,63 & 0,94 & $*$ & 1,25 & 1,53 & 0,94 \\
$\mathrm{~B}$ & 1,50 & 0,83 & 2,39 & 0,83 & 0,38 & 0,42 & 1,21 & 0,31 & 0,94 & 0,42 & 1,25 & 0,25 & 0,56 & 1,72 & $*$ \\
$\mathrm{C}$ & 1,00 & 1,00 & 1,00 & 1,00 & 1,00 & 1,00 & 1,00 & 1,00 & 1,00 & 1,00 & 1,00 & 1,00 & 1,00 & 1,00 & 1,00 \\
\hline
\end{tabular}

hidromórfico, com lençol freático mais raso ou mesmo suspenso. Essa diferença entre os perfis sugere, também, que os perfis 1 e 2 podem ser menos evoluídos que os demais (3, 4 e 5).

\begin{abstract}
AMATÉRIA ORGÂNICA EASUA INFLUÊNCIANAFORMAÇÃO DOS ESPODOSSOLOS As análises da matéria orgânica do ortstein mostram que ela é composta pelos grupos orgânicos $\mathrm{C}=\mathrm{O}, \mathrm{OH}$ e $\mathrm{N}-\mathrm{H}$, ligados, respectivamente, às aminas, fenóis e alcoóis. Esses grupos orgânicos são ácidos e hidrofílicos e, por terem carga negativa, são capazes de diminuir o $\mathrm{pH}$, o que facilita a dissolução de silicatos e óxi-hidróxidos de Fe e a corrosão do quartzo, por meio da formação de complexos e colóides orgânicos (Chorover \& Sposito 1995).

Segundo De Coninck (1980), os cátions monovalentes são rapidamente lixiviados, enquanto os bivalentes e trivalentes formam óxi-hidróxidos mais insolúveis, tendem a imobilizar a matéria orgânica e permanecem no perfil. Assim, segundo esse autor, solos com grande quantidade de minerais instáveis com cátions bivalentes e trivalentes, como os Latossolos, tendem a ser pouco diferenciados, exibindo cores ocres a castanhas, pois a matéria orgânica, ao ser imobilizada, impede a lixiviação mais intensa do perfil, enquanto os horizontes descoloridos têm baixos teores de Fe e $\mathrm{Al}$ e, conseqüentemente, pouca matéria orgânica. Deste modo, solos ricos em quartzo e pobres em $\mathrm{Fe}$ e $\mathrm{Al}$ têm baixa capacidade de reter a matéria orgânica e esta, ao migrar para as partes inferiores do perfil, dissolve a caulinita, corrói o quartzo e se acumula como ortstein, o que permite individualizar os horizontes A e B. A lentidão da migração da matéria orgânica nos Latossolos em relação aos Espodossolos é demostrada pela desferrificação que se observa no topo de vários perfis ao longo da BR-174.
\end{abstract}

Isótopos de carbono Os dados de ${ }^{14} \mathrm{C}$ de uma amostra de carvão do horizonte A do perfil 1 revelam idade moderna e é provável produto de queimadas recentes. Amostras de matéria orgânica de ortsteins dos perfis 3 e 4 e de níveis arenosos do perfil 5 forneceram idade entre 1.960 e 2.810 anos AP (Tabela 5). Os valores de $\mathrm{d}^{13} \mathrm{C}$ entre $-28,6 \%$ e $-29,3 \%$ são típicos de matéria orgânica gerada por vegetação tipo $\mathrm{C}_{3}$ e indica o predomínio de floresta. Esses dados permitem afirmar que o ortstein e as areias orgânicas se formaram, no mínimo, entre 1.960 e 2.810 anos AP, sob cobertura vegetal de floresta tropical em condições de clima úmido.

GÊNESE DAS AREIAS BRANCAS, SUAS RELAÇÕES COM OS LATOSSOLOS E A PAISAGEM A estruturação dos perfis, a presença de ortsteins e bandas de matéria orgânica e o predomínio de quartzo, e, assim, de $\mathrm{SiO}_{2}$ no horizonte $\mathrm{A}$, em detrimento de caulinita, $\mathrm{Al}_{2} \mathrm{O}_{3}, \mathrm{Fe}_{2} \mathrm{O}_{3}$ e $\mathrm{TiO}_{2}$, com teores mais elevados no horizonte $\mathrm{C}$, sugerem evolução progressiva da base para o topo do perfil. Essas características permitem correlacionar as ocorrências das areias brancas na região estudada a Espodossolos. O perfil 3, com espessura do horizonte $\mathrm{A}$ de até $5 \mathrm{~m}$, pode sugerir a presença de Eutisolos (areias quartzosas), mas o condicionamento geológico da região, aliado à presença das bandas de matéria orgânica $\mathrm{e}$ de ortstein, corroboram a hipótese defendida, no presente trabalho, de que os depósitos de areia branca se relacionam à pedogênese, com diferenciação de horizontes e acúmulo de matéria orgânica gerada pela decomposição da floresta.

Apesar da Formação Alter do Chão se estender até o km 90 da BR-174 (Nogueira et al.1997), os Espodossolos ocorrem somente entre Manaus e o $\mathrm{km}$ 60, coincidente com a região de cotas mais baixas e com freqüentes exposições de saprólito e do Arenito Manaus próximo à superfície. Nessa região os perfis lateríticos são imaturos, truncados, sem crosta e com linhas de pedra e manchas esbranquiçadas decorrentes da segregação de ferro. O solo assenta-se sobre o horizonte mosqueado pouco espesso ou sobre as linhas de pedras. Para o norte, os perfis estão preservados, com crosta ferruginosa e incipiente crosta alumino-ferruginosa coberta por Latossolo (Horbe et al. 2001).

Esses dados, e as características dos perfis estudados, permi-

Tabela 5 - Idade e $\mathrm{d}^{13} \mathrm{C}$ da matéria orgânica dos perfis estudados.

\begin{tabular}{|llll|}
\hline Amostra & Material & Idade & $\delta^{13} \mathrm{C}$ \\
\hline Perfil 1- horizonte A & Carvão & Moderna & $-29,3 \%$ o \\
Perfil 3 - ortstein & Quartzo+matéria orgânica & $2810 \pm 70$ & $-29,0 \%$ o \\
Perfil 4 - ortstein & Quartzo+matéria orgânica & $1960 \pm 60$ & $-28,6 \%$ \\
\hline
\end{tabular}


tem relacionar os Espodossolos que ocorrem nas cotas mais baixas com os perfis truncados e, conseqüentemente, a formação destes a partir do horizonte saprolítico da Formação Alter do Chão, inclusive o Arenito Manaus, enquanto que os Latossolos desenvolvem-se sobre os horizontes mosqueados, as linhas de pedra e crostas lateríticas, mais ricos em $\mathrm{Fe}$ e $\mathrm{Al}$, e que marcam as cotas mais elevadas. Considerando que o saprólito arenoso desenvolvido a partir da Formação Alter do Chão, naturalmente menos lixiviado e, portanto, mais rico em quartzo e feldspato que os demais horizontes, e que a matéria orgânica ataca mais facilmente argilominerais, é pertinente concluir que ele reúne as condições favoráveis à formação dos Espodossolos.

A presença de perfis truncados e a natureza do relevo, de colinas com até $150 \mathrm{~m}$ de extensão, interrompidas por vales em $\mathrm{V}$, e com desníveis inferiores a $60 \mathrm{~m}$, sugerem que o entalhamento e/ou denudação foi mais pronunciado na área estudada do que nos terrenos adjacentes a norte e leste, onde ocorrem platôs com 3 a 12 km de extensão e 1 a $2 \mathrm{~km}$ de largura (Horbe et al. 2001). O maior entalhamento e a ocorrência de Arenito Manaus juntamente com as areias brancas reforçam que os Espodossolos da área são produto do intemperismo do saprólito arenoso da Formação Alter do Chão. Portanto, ao contrário do proposto por Lucas et al. (1984), Chauvel et al. (1978), Lucas (1997) e Dubroeucq \& Volkoff (1998) de que os Espodossolos, em geral e na região em particular, resultam unicamente da evolução lateral de vertentes a partir de Latossolos, a clara relação destes com o saprólito arenoso da Formação Alter do Chão permite atribuí-los à evolução vertical dos perfis, a exemplo do observado por Schwartz (1988), Lundström et al. (2000) e Thomas et al. (1999) em outras regiões tropicais. Assim, a evolução vertical seria o fator principal da geração desses perfis, enquanto a componente lateral seria subordinada.

CONSIDERAÇÕES FINAIS Os estudos realizados demons- tram que as areias brancas da região nordeste do Amazonas estão estruturadas nos horizontes A, B e C, que, para o topo, se tornam mais friáveis, arenosos, esbranquiçados e ricos em quartzo. Ocorrem acumulações de matéria orgânica em bandas onduladas no horizonte $\mathrm{A}$ e em ortstein no horizonte $\mathrm{C}$. Essas características, as correlações $\mathrm{SiO}_{2} \times \mathrm{Al}_{2} \mathrm{O}_{3}$ e $\mathrm{TiO}_{2} \times \mathrm{SiO}_{2} \mathrm{e} \mathrm{TiO}_{2} \times \mathrm{Al}_{2} \mathrm{O}_{3}$ e as pequenas variações nos elementos-traço entre os horizontes sugerem evolução in situ, com o horizonte inferior atuando como fonte para o superior. Desse modo, as areias quartzosas são o produto do intemperismo/pedogênese na região, devido à iluviação da matéria orgânica e conseqüente dissolução de caulinita e corrosão do quartzo e, assim, resultando na diferenciação progressiva de horizontes em típico processo de podzolização e geração de Espodossolos.

Os Espodossolos situados entre Manaus e o Km 60 da BR-174 resultaram de saprólitos dos perfis lateríticos truncados da Formação Alter do Chão, como sugerem Schwartz (1988), Lundström et al. (2000) e Thomas et al. (1999) em outras regiões tropicais. Contudo, não se descarta a contribuição, na formação desses solos, exercida pela lixiviação dos Latossolos, como sugerem Lucas et al. (1984), Chauvel et al. (1987), Lucas (1997) e Dubroeucq \& Volkoff (1998). No contexto evolutivo do intemperismo e da lateritização que afetam a região, os Espodossolos representam a fase mais recente, a qual continua em desenvolvimento até os dias atuais, e é muito agressiva, pois os perfis estudados foram desenvolvidos em menos de 3.000 anos, sob floresta.

Agradecimentos Ao projeto O Neocenozóico da Amazônia Ocidental (Proc. n ${ }^{\circ}$ 520243/98-6 PNOPG/CNPq). Ao Profs. Antonio Rossi e Gean Paolo Signolffi, pelas análises de fluorescência e difração de raios-x e à colega Raimunda Larangeira pelo auxílio nas análises granulométricas. Aos revisores da RBG pelas sugestões ao manuscrito.

\section{Referências}

Albuquerque O.R. 1922. Reconhecimento dos vales do Amazonas. DNPM, Bol. Serv. Geol. Min., Rio de Janeiro, 3:1-84.

Bravard S. \& Righi D. 1989. Geochemical differences in an OxisolSpodosol toposequence of Amazônia, Brazil. Geoderma, 44:2942 .

Campy M. \& Macaire J.J. 1986. Géologie des formations superficielles: géodynamique - facies - utilisations. Mason, 344p.

Chauvel A., Lucas Y., Boulet R. 1987. On the genesis of the soil mantle of the region of Manaus, Central Amazonia, Brazil. Experientia, 43:234-241.

Chorover J. \& Sposito G. 1995. Dissolution behavior of kaolinitic tropical soil. Geoch. Cosmoch. Acta, 59:3109-3121.

Cunha P.R.C., Gonzaga F.G., Coutinho L.F.C, Feijó F.J. 1994. Bacia do Amazonas. PETROBRÁS, Bol. Geoc., 8:47-55.

De Coninck F. 1980. The major mechanisms in formation of spodic horizons. Geoderma, 24:101-128.

Dino R., Silva O.B., Abrahão D. 1999. Caracterização palinológica e estratigráfica de estratos cretáceos da Formação Alter do Chão, Bacia do Amazonas. In: Simp. Cretáceo do Brasil, 5, Rio Claro, 1999. Boletim de resumos. Rio Claro, p.557-565.
Dubroeucq D. \& Volkoff B. 1998. From Oxisols to Spodosols and Histosols: evolution of the soil mantles in the Rio Negro Basin (Amazonas). Catena, 32:245-280.

Fernandes Filho L.A., Costa M.L., Costa J.B.S. 1996. Registros neotectônicos nos lateritos de Manaus. Geociências, 16:9-33.

Franzinelli E. \& Rossi A. 1996. Contribuição ao estudo petrográfico e geoquímico do Arenito Manaus. In: Simp. Geol. Amaz., 5, Belém, Anais, p.209-211.

Horbe A.M.C., Nogueira A.C.R., Horbe M.A., Costa M.L., Suguio K. 2001. A lateritização na gênese das superfícies de aplanamento da região de Presidente Figueiredo-Balbina, nordeste do Amazonas. In: Contribuições a Geologia da Amazônia, 2:148-176.

Leal P.C. 1996. Caracterização e interpretações genéticas de alguns solos da região de Manaus, AM. Dissertação de Mestrado. UFPe. 109p.

Lucas Y. 1997. Biogeoquímica em ambiente equatorial: exemplo dos sistemas Latossolos-Podzóis da Amazônia. In: Cong. Intern. Geoq., 4, Anais, pp: 9-12.

Lucas Y., Chauvel A., Boulet R., Ranzani G., Scatolini F. 1984. Transição latossolos-podzóis sobre a Formação Barreiras na região de Manaus, 
Amazônia. Rev. Bras. Cienc. Solo, 8:325-335.

Lundström U.S., Van Breemen N., Bain D. 2000. The podzolization process. A review. Geoderma, 94:91-107.

Nogueira A.C.R., Souza V.S, Soares E.A.A. 1997. Contribuição à tectônica cenozóica da região de Presidente Figueiredo, norte do Amazonas. In: SBG, Simp. Nac. Estudos Tectônicos, 6, Pirinópolis, Volume de Resumos, p. 123-125.

Nogueira A.C.R., Vieira L.C., Suguio K. 1999. Paleossolos da Formação Alter do Chão, Cretáceo-Terciário da Bacia do Amazonas, regiões de Presidente Figueiredo e Manaus. In: Simp. Cretáceo do Brasil, 5, Rio Claro. p.261-266.

RADAMBRASIL. 1978. Projeto RADAMBRASIL, Folha AS-20, Manaus. DNPM/MME. Rio de Janeiro. 567p.

Roose E. 1980. Dynamique actuelle des sols ferrallitique et ferrugineux tropicaux d'Afrique Occidentale. Thèse Doct. Univ. Orléans. 586p.
Santos J.O.S. 1993. O pantanal setentrional e os campos de dunas da Amazônia Ocidental. In: Intern. Symp. Quarternary of Amazônia. Resumos. p.110.

Sarges R.R. 2001. Geologia e compartimentação geomorfológica da região de Presidente Figueiredo. Relatório Interno. FUA/ICE/ DEGEO. 37p.

Schwartz D. 1988. Some podzol on Bateke Sands and their origins, People's Republic of Congo. Geoderma, 43:229-247.

Thomas M., Thorp M., McAlister J. 1999. Equatorial weathering, landform development and the formation of white sands in north western Kalimantan, Indonesia. Catena, 36:205-232.

Manuscrito A-1317

Recebido em 09 de janeiro de 2002

Revisão dos autores em 10 de janeiro de 2003 Revisão aceita em 15 de janeiro de 2003 